\title{
The Frustration of a Pure Contest
}

Colin Jones

University of Tasmania

Private Bag 16

Hobart 7001

Australia

Phone: +61 362262826

Fax: +61 362262808

Email: Colin.Jones@utas.edu.au 


\title{
The Frustration of a Pure Contest
}

\author{
Research Paper
}

\begin{abstract}
Purpose: This paper discusses the development of a strategy game for enterprise education. It is argued that requiring students to initially struggle with the game's rules and strategies results in a worthwhile test of their persistence and ability to manage ambiguity. Further, that in the absence of uncertainty, students will not benefit from the game's potential contribution to their overall learning.

Approach: The paper is constructed around the infusion of student narratives and the author's self-reflective thoughts. The papers explores the process of developing a game that; 1) provides the students with access to an enterprise reality, 2) strengthens their engagement with the theoretical foundations of their studies, and 3) provides a process for serious self-reflection.

Findings: Despite the mixed views presented in this paper, the game's development thus far has been very successful. Students do enjoy and benefit from enduring the frustration of a pure contest. Having to work through uncertainty is a good practice for students in Higher Education, especially those engaged in enterprise education.

Practical Implications: Whilst the use of games in experiential education is not uncommon, consideration of how and why they are developed is not always well understood. This paper suggests that enterprise educators have significant opportunities to develop games that genuinely provide student access to the entrepreneur's way of life.

Value of Paper: This paper provides evidence of how a game can be constructed to add significant value to an existing curriculum. It also provides evidence of the inner thoughts of students frustrated by a challenge they refuse to give up on. As such, it provides a valuable window through which to contemplate the minds of tomorrow's nascent entrepreneurs.
\end{abstract}

Keywords: Enterprise Education, Strategy Games, Hic et nunc

\section{Introduction}

This paper reflects on the successful development of a strategy game that allows students to learn through and for enterprise (Gibb, 2002). During the past four years a unique 
learner-centred approach to enterprise education has been developing at the University of Tasmania. The approach, known as the hic et nunc teaching framework, has been previously discussed elsewhere in great detail (Jones, 2005; 2006a; 2006b; 2006c; 2006d). Constructed around the early teaching philosophies of Whitehead (1929) and contemporary ideas of Gibb (e.g. 2002), the hic et nunc framework provides the opportunity for students of enterprise to learn through and for enterprise in their here and now. One learning activity within this framework is the Resource Allocation Game, students (in pairs) must confront a cryptic scenario and make decisions as to 1) when their firm will enter the industry under consideration, 2) what type of strategy and structure will they employ, and 3) to give consideration to what extent they may be able to influence the nature of environmental selection acting upon the industry.

Before outlining the nature of the Resource Allocation Game, a very brief overview of the hic et nunc framework will be provided to establish the context and purpose of the game within the overall teaching process. Inspired by the literal Latin conversion of the term, here and now, the hic et nunc framework encourages and enables each individual student to learn in their here and now (Whitehead, 1929), accommodating the development of differing interpretations of the required learning topics. A key factor in the learning process has been the provision for continuous student reflection (Tyler, 1949) related to the repeated learning activities that occur during the fortnightly workshops. Over time the learning activities have evolved to include games, case study discussion, workshop presentations and reflective diaries that are all tied to the topics 
introduced cumulatively throughout workshops. The configuration of the learning activities is illustrated in Figure 1 below.

\section{Insert Figure 1 Here}

The purpose of the learning activities developed and continually refined is to accelerate the "process of changing the behavior patterns ... [of the students] ... using behavior in the broad sense to include thinking and feeling as well as overt action” (Tyler, 1949, pp. 5-6). There are two specific aims of the program. One relates to assisting students to be capable of making the journey from student to graduate entrepreneur and the other (more general) aim relates to helping the students develop the attributes of a reasonable adventurer. Heath (1964) defines the reasonable adventurer as a graduated student capable of making his or her own opportunities for satisfaction. A disposition argued to be a necessary pre-condition for engaging in entrepreneurial behaviours.

A key in jolting the students into reflective practice is to enable them to engage in learning activities that are both extremely challenging and personally rewarding. Student feedback suggests the Resource Allocation Game is both challenging and rewarding for the students. The game has two specific aims. Firstly, it provides each student with a regular opportunity to play with the main theoretical concepts discussed and used throughout the semester. This requires that students develop a high-level of understanding of how specific theoretical concepts (e.g. specialists, generalists, $r$ and $\mathrm{K}$ 
strategists, fundamental and realized niches, industry carrying capacity, niche construction, resource profiles, and many other evolutionary concepts used in the curriculum) relate to each other. Secondly, the game offers each student an opportunity to develop strategizing skills.

Whilst playing the game, students can be separated by skill, dexterity, effort and eventually ... luck! The game is unpredictable because each student cannot know what strategies the other players will consider and/or play. All they can do is endeavor to play a strategy that puts then in the path of lady luck. Essentially, the best strategies will emerge as superior from all other submitted rival strategies. A clear challenge exists for the students to reconcile how their skill, dexterity and effort relate to any fortuitous luck. At first this may seem unfair that assessment is tied to luck, but consider the comment by Stan Metcalfe below (Metcalfe, 1998, p. 20):

"The final element of any contest is the inherent unpredictability of the outcomes. In part this may arise from uncertainty about the environment of the contest, since not all contingencies can be written into the rules, and in perhaps greater parts from a lack of predictability about the behaviour of the contestants. Neither the outside observer nor the contestants can observe or anticipate the plans and strategies of the various rivals or predict the multiplicity of contingent circumstances which affect performance at a particular play. Luck is an essential part of all contests, 
the fall of the favorite, the emergence of the darkhorse, and as this degree of unpredictability declines so often does the desire to call it a contest. In this regard, contests are discovery procedures to find the best behaviour out of a set of rival behaviours.”

The Resource Allocation Game has established a reputation as a game that cannot be taken for granted. Whilst it is very difficult to master, it continually draws in those students that have failed to conquer its inherent challenges. This is one of the games greatest strengths, it allows students to experience failure and go back to the drawing board to regroup. It strips students of their past academic pride and reveals the fragility of contesting a competitive market. Students learn from their failures, they acknowledge the role of luck and timing in the outcomes they experience, and most importantly, they learn to anticipate what other (competitive) behaviours are (or likely to be) occurring around them. The next section of this paper will outline the task confronting students playing the Resource Allocation Game.

Each student is paired with another student and given a maximum of thirty (30) credits to invest into an industry. Each game has a unique cryptic scenario that picks up on the specific theory (e.g. spin outs, socio-political legitimacy, etc) that students have discussed in their workshops presentations. The investment decisions they face are many. Will they enter the game during the industry's start-up phase, during its growth phase, or during the decline/rejuvenation phase? Will they spread their investment across the phases, and if 
so, what strategy will accompany their investment? The students can choose four main strategy/structure configurations. The can be either a specialist or generalist depending upon the size of the realized niche they wish to capture. They can align these strategies to an operating form that seeks to exploit a fast paced and unpredictable environment (i.e. an r-strategy) or one that seeks to take advantages of economies of scale (i.e. a Kstrategist).

The cryptic scenario also includes hints as to the nature of expected (pre-set) payoffs that certain behaviours could expect to receive. However, the students can also attempt to alter the pre-set environmental payoffs by redirecting up to five (5) of their credits to gain greater potential influence over the industry environment. Aside from trying to understand what behaviours are suggested by the cryptic scenario to be favored, the students must also anticipate what the other strategies their classmates will play. Opportunities may exist to play risky strategies that aim to capture seemingly unattractive or marginal niches that will be ignored by most players seeking safer strategies. Just as in real life, crowded niches will provide diminishing returns, and greater returns are always possible from owning a niche.

\section{The Theoretical Underpinnings of the Game}

The game is structured around five core readings. A cryptic scenario that relates to each of the readings is given to the students to solve. An explicit evolutionary perspective is used throughout the entrepreneurship programme. With this approach, the students are 
able to develop an understanding of the process of social change. Aldrich and Martinez (2001, p. 42) advocate the use of evolutionary theory to the study of entrepreneurship, noting that:

"Evolutionary theory unites in a single coherent framework a concern for the entrepreneurial outcomes and the processes and contexts making them possible. An evolutionary approach studies the creation of new organizational structures (variation), the way in which entrepreneurs modify their organizations and use resources to survive in changing environments (adaptation), the circumstances under which such organizational arrangements lead to success and survival (selection), and the way in which successful arrangements tend to be imitated and perpetuated by other entrepreneurs (retention)".

The first article used (Aldrich and Martinez, 2001), from which students gain an understanding of the importance of the process, context, and outcomes of entrepreneurship. Then, sections of Aldrich's (1999) landmark monologue outlining the nature of an evolutionary approach, the formation of populations and the issue of legitimacy are introduced. This is followed by the work of Agarwal, Echambadi, Franco and Sarker (2004) concerning the nature of knowledge transfer, the occurrence spin-outs and issues of survival is introduced. The last piece of literature used is an article by Levinthal (1991) related to the interrelatedness of the selection and adaptation processes. 
An example of such a cryptic scenario (and incorporated solution) is presented below. This scenario relates to the issue of cognitive and socio-political legitimacy.

The industry, you will enter has a short, but unpredictable history. The industry is the online Book Retailing industry. When the industry began in the mid 1990s, very little cognitive or socio-political legitimacy surrounded the concept of online bookselling. Many small start-ups, tried to establish a market presence, lured by the vast reach and potential of the World Wide Web. The market seemed attractive with Amazon.com, creating much interest in online retailing. But few, if any firms were able to turn a profit (therefore, don't invest in either $\mathrm{r}$ or $\mathrm{K}$ during phase 1 of the game). Through the industry's mid-period, many small start-ups entered and established niche positions selling a rare and second-hand books (therefore, enter as a specialist, either $\mathrm{r}$ or $\mathrm{K}$ ). Throughout this period, much cognitive legitimacy developed for the idea of online book selling. However, despite the emergence of is on.com as the first super online brand, the degree of so show political legitimacy surrounding online book retailing was limited, with many consumers still preferring to look online, but by offline. It would seem that success was based around one essential fact. Small start-ups that managed to develop a highly unique niche during the industry's mid-period and simultaneously developed the capacity to operate efficiently have prospered ever since. As such, those firms who survived to this day continued to be very world awarded for their past foresight (therefore, invest everything in phase 2, either r-s or K-s, the computer will transfer $50 \%$ 
of $2^{\text {nd }}$ phase r-s and /or K-s to $3^{\text {rd }}$ phase K-s) in the developing their unique niche and efficient operations.

The students would not have the advantage of the solution being included within the initial scenario. This would be provided to them after they have completed the game. Their challenge is to determine what he is the 'standard' strategy that could be played. In this case, it would be to enter the industry during the second phase, and invest as a specialist. Alternatively, they may decide to devise a nonstandard strategy that may attempt to exploit a niche that they sense may provide superior payoffs.

\section{Enduring the Frustration}

The remainder of the paper considers the educational benefits of the game, presenting student feedback regarding their experiences playing the game. Perhaps the most pleasing aspect of the game is that it truly mirrors many of the challenges of decision making in real life. That students misperceive the capacity of their 'start-up' to out-compete other start-ups and/or incorrectly interpret environmental signals is to be expected. The nature of their mistakes can be reconciled using the typology of misperceptions created by Langlois (1997) that highlights errors associated with market and operational misperceptions. It is through appreciation of their respective abilities to always know the right way to play that they develop respect for the role luck plays in enterprise. A role that cannot be taken for granted or ignored, but merely accepted. With regards to the 
question of whether or not the game represents a good way to engage with the theory covered in the unit, a selection of students' views reveals mixed positions:

Yes I do, as it is applying the theory to practice, which is honestly a better way of learning than just reading about it, in the same way that presentations make the theory more real. Although there may be a need for more discussion on why a particularly good strategy is useful, and why that would be relevant to an $r$ or $K$ [strategist or] specialist/generalist (anonymous student comment no. 1).

I'm not sure, because I get the theory, but I find the game hard to apply the theory to. Don't get me wrong, I like the idea, but I think that the descriptions are just too full of complex wording to be able to wrap my head around (anonymous student comment no. 2).

Yes, I think the game is a good way to learn the theory. Initially, I cringed, but I have to say it makes you think about the strategies, and then think about what others will do and then when you think you can influence the environment, it makes you think about the possible theories and outcomes (anonymous student comment no. 3). 
Clearly, some students are more pragmatic in accepting the vagaries of the game. The transition from students engaged in a learning process connected to marks to those engaged in a learning process connected to their personal development is hinted at. It would seem that the game can be viewed as a task to be completed, or a challenged to be savored. When the issue of incorporating a process of struggle into the learning process is considered, again, mixed views surface:

No. I think it would actually be quite stressful for a lot of people to try to work it out. Particularly as it is introduced right at the beginning, when we haven't even heard the terms and don't necessarily understand them. Maybe if was introduced after the workshop where the $r$ and K. stuff was covered. There also seems to be an implication that we students understand the bad environments, and which is the best strategy to play. For example, I might read this scenario, and understand, yes, this is a phase, whatever, and the market appears to be dominated by K strategists, but I wouldn't really know whether it is better to do the same thing or branch out and be a specialist. I guess that is all part of the learning process, but it can be unsettling. I think I might be better to know at least the terms and what they mean first, and then try the game. Also, because the method of learning is so different to other subjects, there are a lot of new things all once, trying to establish a team, a partner for the game, work out the first presentation and so on, there is a lot of uncertainty 
already, and a fair bit of pressure with the two presentations, being only a week apart (anonymous student comment no. 4).

I think that you should have an easier format rather than struggling to learn the format. With the student driven learning approach, students just have too much on their plates to have their heads around a foreign concept (anonymous student comment no. 5).

When I think about the level of frustration and confusion I feel in class, I can see that it is at a level where it pushes you to try and learn harder and better and prepares us for the frustrations and confusions we may face in the real world. When I play the game, I still don't think I have an understanding of how to come up with a winning strategy and feel that I may never have this ability. But I guess there will be many situations in life where you may not know how to win a situation, but you must know how to do your best to stay in the game (anonymous student comment no. 6).

I think is useful to struggle to learn the theories because it makes you analyze options (anonymous student comment no. 7). 
To be honest, the game frustrates and annoys me. When I think I have worked it out ... the marks reflect [another] good strategy, this leaves me even more confused for the next game. (anonymous student comment no. 8).

Again, for some (though a minority) the structure and process of the game begin too chaotically. It has developed a life of its own before many of the students reach a point where they gained a minimal degree of understanding. It would seem fewer students are able to accept the fairness of such a 'rushed' start to proceedings. The issue of accommodating luck into the game, specifically as it relates to assessment also still remains a contentious issue:

The game is one of my favorite parts of the unit. Something about its uniqueness and combination of luck and skill really draws me to it and I look forward to it each fortnight. The only negative remarks I have about the game is that I can never find a niche. I would really love to win the game once, and I think that chasing a niche simply won't work (anonymous student comment no. 9).

Well, yes and no. Yes, in that, if it were a real-world situation, luck is certainly factored in. No, because I don't know that everyone in the room understands what is going on. And if you don't understand it, and just 
play whatever strategy you like, then learning may not occur. You could go through the whole semester not understanding and lose or win based on luck, and I personally would not be comfortable with having marks at the end of the semester based on luck. I think they [i.e. the class] have a pretty good grasp on it now, and it is unsettling to think you understand something, you play the strategy that is based on your understanding, and in the end, you don't get rewarded for it because someone else got lucky, particularly if it is blind luck, and they had no understanding themselves. I know it is only a small percentage of the marks, but you could end up at the end of the semester. Having total understanding of the material and how it applies, but no marks to reflect that understanding (anonymous student comment no. 10).

Yes. Lucky exists, there is no denying it so I really like the idea that it is built into the game. It is definitely a different concept than I have experienced, but I like it (anonymous student comment no. 11).

Luck is the wild card in life, so it is appropriate in the game. Many entrepreneurial ventures, regardless of how successful they should be, don't make it. (anonymous student comment no. 12). 
Overall, as the semester has progressed, students have become more willing to accept the role of luck in the game. They have come to accept that if you don't understand what the preferred 'standard' strategy is, then you can only hope to rely on luck, but in a crowded marketplace, lucky outcomes are difficult to achieve. Most importantly, the students have begun to reconcile the relationship between luck and the management of risk. That is, departing from the obvious to pursue the potential of greater payoffs via a 'non-standard' strategy includes an increase in risk, risk that is a double-edged sword. In relation to the degree of difficult of the cryptic scenarios, students had the following comments to make:

I think I understand them okay. I read through them and make comments about the phases, and what I think. Then I send it to my partner, and he has something different. Then I get confused, because even though I think my understanding is good, his explanations are also convincing, so I don't know then, and lose some confidence. It is comforting to have the solution put up [in the workshop] with similar things that I have written down (anonymous student comment no. 13).

Yes, too hard to understand. The wording is just too difficult to get your head around. Usually, even after you have explained it to the class! (anonymous student comment no. 14). 
The game scenarios are great! They drive me nuts. I sit for hours thinking through which way I will jump, and then I go and change it when I send it. I think it is a good way to learn. It teaches us to read the environment, that nothing is black-and-white in the business world (anonymous student comment no. 15).

\section{Discussion}

Reflecting on the comments that the students have made, provides interesting insights into their varied learning styles. As noted previously by Heath (1964), students will commence their learning from different temperament-based starting points. Perhaps one of the game's strengths is its ability to allow students to confront a problem / opportunity that requires their simultaneous exploration and exploitation. At the heart of the hic et nunc teaching framework is a desire to not only let the students learn in there here and now, but also ensure that their application of knowledge is related to a disciplined assessment process. Like all evolving processes, the Resource Allocation Game has its fair share of inbuilt problems. The most serious issue is ensuring the right balance between student freedom and associated curriculum discipline.

As recently discussed in Jones (2007), a failure to achieve a balance between freedom and discipline threatens the educational processes that Whitehead (1929) described as the rhythm of education. Whitehead argued that a productive learning environment was the primary concern of any educational facilitator. That the essential challenge was to 
determine how to create student interest in any specific learning activity, whilst also ensuring student interest is transferred towards an applied outcome. Further, once student interest is created and their knowledge demonstrated, other opportunities through which increased interest is developed, must be cultivated to ensure the development of wisdom. The Resource Allocation Game represents such a learning activity through which each student's interest and knowledge demonstration is possible. It provides a possible point of departure for each student to become fully responsible for their decisions. Rather than assuming that the correct answer will be revealed and an increment of required knowledge acquired, students must develop judgement and intuition in order to participate in a game where the nature of the environment is yet to be fully revealed. The game does not seek to confuse the students unnecessarily, but it is a relatively unforgiving of students who fail to grasp of the essence of the limited theoretical concepts examined in the unit.

The game's assessment procedures facilitate both formative and summative feedback. Both assessment processes are critically important in to the development of entrepreneurial skill and knowledge. This process of generating both summative and formative assessment performs two important functions. First, the summative feedback (i.e. the actual mark they receive) provides an indication of the immediate fitness of the students' degree of understanding vis-à-vis their fellow students at that particular moment in time. Second, the formative feedback (i.e. the workshop post game discussion) provides feedback through which future change is possible. The difference between both 
forms of assessment being "that at some point the judgement has to be final” (Biggs 2003, p.142). In the spirit of Gibb (2002), the game has the potential to increase student persistence and tolerance of ambiguity.

Observing that the manner in which students play the game through their submitted strategies, reflections, and workshop discussion provides the educator with a valuable insights into each student's psyche. We are able to see differences in student personality that manifest themselves as positive or negative determinants of entrepreneurial behaviour. Through allowing our students to fail we allow them to succeed. The challenge is that we must recognise that while our students truly do differ, there is a common outcome they can work towards. Heath (1964) calls this common outcome the becoming of a reasonable adventurer, that is, someone capable of making their own opportunities for satisfaction.

\section{Conclusion}

This paper has detailed the development of an innovative enterprise game. The game confuses students before allowing them to develop a greater sense of understanding of the theory used within the unit. The degree to which students must struggle to overcome any sense of confusion related to the game is a test of their persistence and ability to manage ambiguity. It also provides a unique way in which students can experience the trade-off between incorporating risk into their behaviours and/or deciding to play safe. Within the context of enterprise education these are very useful learning outcomes. The game offers 
a relatively safe haven for those students who are willing to fail in order to succeed. It does not provide comfort for those students who are not willing to demonstrate the persistence required to overcome the inherent chaos associated with each new game.

Student feedback provides evidence that the game while frustrating, is a very popular way for the students to engage in the theory at hand. The lessons to be learnt from the development of this game, is that as educators, we can advance our students' outcomes by forcing them into a zone of discomfort or significant challenge. That the benefits in the long run of allowing students to experience failure, misjudgement, overconfidence, and the excitement of believing in their abilities far outweigh the ups and downs of experiencing a pure contest.

\section{References}

Agarwal, R., Echambadi, R., Franco, A.M., and Sarkar, M.B. (2004), "Knowledge transfer through inheritance: Spin out generation, development, and survival”, Academy of Management Journal, Vol. 47 No. 4, pp. 501-522.

Aldrich, H.E. (1999), Organizations Evolving, Sage Publications, London.

Aldrich, H.E., and Martinez, M.A. (2001), "Many are called, but few are chosen: An evolutionary perspective of the study of entrepreneurship", Entrepreneurship Theory and Practice, Vol. 25 No. 4, pp. 41-56.

Biggs, J. (2003), Teaching for Quality Learning at University: What the Student Does, $2^{\text {nd }}$ Ed, Open University Press, London.

Gibb, A.A. (2002), “Creating conducive environments for learning and entrepreneurship: Living with, dealing with, creating and enjoying uncertainty and complexity”, Industry \& Higher Education, Vol. 16 No. 3, pp. 135-148.

Heath, R. (1964), The Reasonable Adventurer, University of Pittsburgh Press, Pittsburgh. 
Jones, C. (2006d), “Enterprise education: Introducing Whitehead to Gibbs”. Education + Training, Vol. 48 No. 5, pp. 356-367.

Jones, C. (2005), “Creating employability skills: Modification through interaction”. Journal of Industry and Higher Education, Vol. 19 No. 1, pp. 25-34.

Jones, C. (2006b), "Guided by the philosophy of constructive alignment, directed by the realisation of niche construction". Proceedings of the $29^{\text {th }}$ HERDSA Conference: Critical Visions. July 10-13, Perth, Australia.

Jones, C. (2006c), “Enterprise curriculum: Guided by ghosts, experts and our students' here and now". Proceedings of the $51^{\text {st }}$ ICSB Conference. June 18-21, Melbourne, Australia.

Jones, C. (2006a), “Stepping back to look inside the entangled bank”. Proceedings of the $3^{\text {rd }}$ AGSE International Entrepreneurship Research Exchange. February 8-10, Auckland, New Zealand.

Jones, C. (2007), “Contemplating Whitehead's freedom and Discipline”. Journal of University Teaching and Learning Practice, Vol. 4 No. 1, pp. 1-12.

Langlois, R.N. (1997), "Cognition and capabilities: Opportunities seized and missed in the history of the computer industry”. in Garud R., Nayyar P., Shapira Z.: (Eds), Technological Innovation. Cambridge University Press, New York, pp. 71-94.

Levinthal, D.A. (1991), “Organizational adaptation and environmental selection interrelated processes of change”, Organization Science, Vol. 2 No. 1, pp. 140-145.

Metcalfe, J.S. (1998), Evolutionary Economics and Creative Destruction, Routledge, London.

Tyler, R.W. (1949), Basic Principles of Curriculum and Instruction, University of Chicago Press, London.

Whitehead, A.N. (1929), The Aims of Education and Other Essays, Free Press, New York. 
Figure 1 - The hic et nunc framework

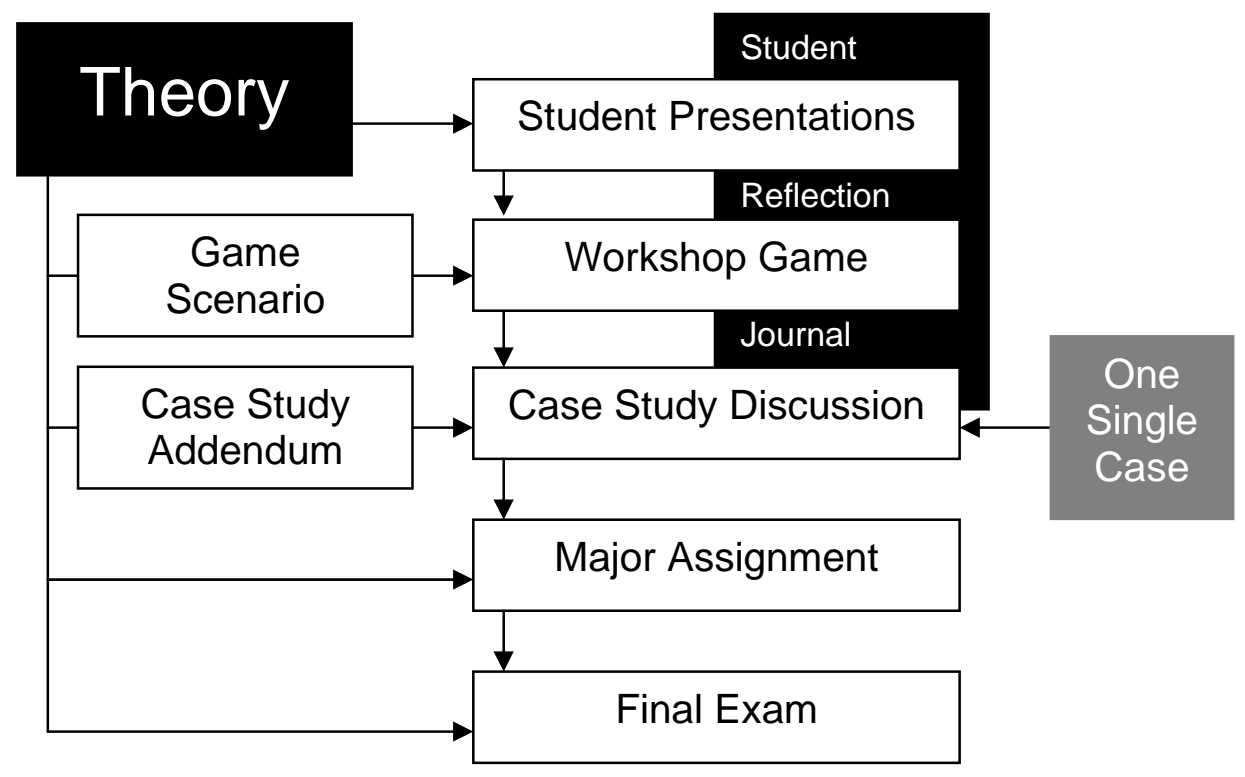

